\title{
An Analysis of Electrocardiographic Criteria for Determining Left Ventricular Hypertrophy
}

\author{
Carlos Alberto Gasperin, Helio Germiniani, Carlos Roberto Facin, Admar Moraes de Souza, \\ Cláudio Leinig Pereira da Cunha \\ Curitiba, PR - Brazil
}

\begin{abstract}
Objective - To determine the most sensitive criterion for the detection of left ventricular hypertrophy according to echocardiographically defined left ventricular mass.
\end{abstract}

Methods - The Sokolow-Lyon voltage, Sokolow-Lyon-Rappaport, Cornell voltage duration product, WhiteBock, and Romhilt-Estes point scoring criteria were compared with left ventricular mass index, corrected for body surface, obtained from the echocardiograms of 306 outpatients (176 females, 130 males), of all age groups.

Results - The Cornell voltage duration product criteria index had the greatest sensitivity in women (54.90\%), and the Sokolow-Lyon-Rappaport index was most sensitive in men (73.53\%). When applied to men at the same voltage amplitude (20mm) as that in women, the Cornell index showed increased sensitivity relative to the conventional index $(28 \mathrm{~mm})$ of $67.65 \%(P \leq 0.01)$ and a sensitivity similar to that of the Sokolow-Lyon-Rappaport index, with higher specificity $(P \leq 0.01)$. The White-Bock and Romhilt-Estes criteria were the least sensitive in men and women, despite their high specificity. The electrocardiographic criteria were more efficient when dilatation predominated over left ventricular hypertrophy.

Conclusion - The Cornell index had greater sensitivity in women, and the Sokolow-Lyon-Rappaport index was more sensitive in men. When applied to men at the same voltage amplitude as that of women, the Cornell index had an increase in sensitivity similar to that of the SokolowLyon-Rappaport index.

Keywords: left ventricular hypertrophy, hypertrophy, electrocardiogram

Hospital de Clínicas de Curitiba - Universidade Federal do Paraná

Mailing Address: Carlos Alberto Gasperin - Rua Grã-Nioco, 295/1001- 81200200 - Curitiba, PR, Brazil - E-amil: gasperin@cardiol.br
Increases in left ventricular mass have been associated with increases in the magnitude and duration of the QRS complexes ${ }^{1,2}$. Several criteria exist for the electrocardiographic detection of left ventricular hypertrophy (LVH). From the earliest times of electrocardiographic use, many indexes for the magnitude and duration of QRS complexes and AQRS have been developed. Electrocardiographic evidence of left ventricular hypertrophy is one of the most widely used markers of cardiovascular morbidity and mortality ${ }^{3,4}$. It has become a clinical priority to precociously detect left ventricular hypertrophy by effective, low-cost screening, applicable to the population in general ${ }^{5-8}$. Numerous publications have emphasized the need for such precocious detection, useful as an important prognostic index of $\mathrm{LVH}^{9}$. Currently, low cost and ease of application have rendered electrocardiography the preferable means to this end.

Yet, despite their high specificity, at present electrocardiographic indexes still suffer from their low sensitivity. The present study attempts to correlate findings obtained with 5 different electrocardiographic criteria with data on left ventricular mass obtained by echocardiography. The SokolowLyon voltage, Sokolow-Lyon-Rappaport, Cornell voltage duration product, White-Bock, and Romhilt-Estes point score criteria were chosen for our study because we currently use them and because of their long-standing international recognition. The recently developed Cornell criterion ${ }^{10}$ has been extensively used in studies in North America. For this reason, it has been included in this correlation study.

In this study, we determined the electrocardiographic criterion that had the greatest sensitivity for detecting left ventricular overload in men and women. We then correlated age, anterior-posterior thoracic diameter, thoracic perimeter, and left ventricular mass with voltage amplitudes used for electrocardiography.

\section{Methods}

Outpatients from the echocardiography clinic of the 
Hospital of the Federal University of Paraná, Curitiba were examined. Participants were informed about the aims of the project, its approval by the Medical Ethics Committee of the Hospital, and gave their written consent to be participants in the study.

The selected cohort was consecutively obtained between March 15, 1997 and December 20,1997, by random choice of outpatients scheduled for echocardiography. Evaluations included clinical examination, an electrocardiogram (ECG), and anthropometric and arterial measurements prior to echocardiography. ECGs were numbered randomly to prevent later identification. Comparison of the analytical results with the patient's identity were performed only after all data had been collected. Causes for exclusion from the cohort were: a previous myocardial infarct, sinus node disease, dilatation aneurysm of the left ventricle, Wolff-Parkinson syndrome, blockade of electrical conduction of the right or left bundle of His, ventricular or supraventricular tachycardia, cardiac pacemaker use, patients with ECG or echocardiograms of inadequate technical quality.

A total of 306 (176 women, 130 men) patients were studied. Subjects less than 12 years of age included 34 females and 41 males. Eighteen men and 21 women were non-Caucasian. The patient universe comprised normal individuals and those whose echocardiograms showed increased left ventricular mass; 19 women and 21 men had undergone valve replacement mostly of the mitral valve; 5 women and 8 men had metallic prostheses.

Age, sex, race, results of the clinical examination, arterial pressure, weight, height, thoracic anterior-posterior diameter, and thoracic perimeter at the height of the fifth intercostal space were recorded. Body mass index was determined by weight $(\mathrm{kg})$ divided by height $\left(\mathrm{m}^{2}\right)$. Body surface was obtained using the Dubois and Dubois formula ${ }^{11}$.

Medications, especially digitalis and antiarrhythmics taken regularly, were recorded. Questions about previous cardiac surgery and valve replacement were asked.

ECGs were obtained after the clinical examination. Children less than 1 year of age and those who would not stay still during the examination were sedated with $8 \%$ chloral hydrate at a dose of $0.5 \mathrm{~mL} / \mathrm{kg}$ to allow obtainment of adequate electrocardiographic recordings. Tracings were taken with a Funbec-ECG05 electrocardiograph at $25 \mathrm{~mm} / \mathrm{sec}$ after proper calibration for an amplitude of $1 \mathrm{mV} / \mathrm{cm}$.

The same examiner, using a Hewlett-Packard Sonos 1000 apparatus with a $2.5 \mathrm{~mm} \mathrm{~Hz}$ transducer, obtained echocardiograms from all patients. Images were taken by orienting images at the two-dimensional mode on the transversal plane of the left ventricle after left parasternal positioning of the transducer at the height of the papillary muscles ${ }^{6,12,13}$. The ECG DII derivation was recorded simultaneously with the echocardiographic images. ECGs and echocardiograms of each patient were taken on the same day.

Electrocardiographic criteria for determining left ventricular hypertrophy were as follows: Sokolow-Lyon sum of the largest $\mathrm{R}$ wave of the V5 or V6 derivation with wave $S$ of the V1 $\geq 35 \mathrm{~mm}$; Sokolow-Lyon-Rappaport - sum of the largest $\mathrm{R}$ wave of derivation $\mathrm{V} 5$ or $\mathrm{V} 6$ with wave $\mathrm{S}$ of the $\mathrm{V} 2 \leq 35 \mathrm{~mm}$; Cornell - sum of the amplitude of the $\mathrm{R}$ wave at derivation AVL with wave $\mathrm{S}$ at derivation $\mathrm{V} 3 \geq 28 \mathrm{~mm}$ in men and $\geq 20 \mathrm{~mm}$ in women; White-Bock - sum of wave $R$ at the DI derivation with Wave $S$ at the DIII derivation, minus the sum of wave $R$ at the DII derivation with wave $S$ at the $\mathrm{DI} \geq 17$; Romhilt-Estes point scoring - takes amplitudes of waves $\mathrm{R}$ or $\mathrm{S}$ in limb and precordial derivations, alterations of segment ST-T, wave $\mathrm{P}$ at V1 derivation, deviation and duration of QRS and initial time of the intrinsicoid deflection of QRS, into consideration.

Left ventricular mass determined the echocardiographic criterion of LVH chosen ${ }^{14}$. The mass of the left ventricle was measured using the criteria of the American Society of Echocardiography, modified ${ }^{15}$ by the formula [(diastolic thickness of the intraventricular septum + diastolic thickness of the posterior wall of the left ventricle) $\left.{ }^{3}\right] \mathrm{x}$ $1.04 \times 0.8+0.6$. All measurements were taken at the end of ventricular diastole, corresponding to the beginning of the QRS complex recorded on the simultaneously taken electrocardiographic tracing.

The determination of the normal value of left ventricular mass in adults was established according to Levy et al ${ }^{16}$ as being less than $166 \mathrm{~g}$ or $100 \mathrm{~g} / \mathrm{m}^{2}$ in women and $259 \mathrm{~g}$ or $131 \mathrm{~g} / \mathrm{m}^{2}$ in men. The second values were corrected for body surface, respectively. Mass in adults was also estimated according to the normality curve cited by Feigenbaum ${ }^{17}$ and after the study of Abergel et al ${ }^{18}$. Normality criteria for left ventricular mass in children were defined by the studies of Simone et al ${ }^{19}$ and Daniels et al ${ }^{20}$ and were in agreement with the normality curve cited by Feigenbaum ${ }^{17,21-23}$.

Study participants were considered clinically and echocardiographically normal if they were free of alterations in the cardiac chambers, valve changes of hemodynamic significance, a transvalvular gradient detectable by color flow Doppler, had a systolic arterial pressure below $140 \mathrm{mmHg}$ and a diastolic pressure below $90 \mathrm{mmHg}$, had no abnormalities on clinical examination, and were not using medication. These normal participants were selected as examples of normality tracings of left ventricular mass, taking into consideration their sex, age, body mass index, and body surface. Cases with left ventricular mass greater than all values and curves considered as normal were considered patients with increased left ventricular mass. Left ventricular mass determined by echocardiography was considered as the gold standard, and results of this examination were accepted as the true ones. The various results of the 
determinations of left ventricular hypertrophy obtained by the electrocardiographic criteria applied to each case were compared with the left ventricular mass obtained by echocardiography. The degree of agreement in the methods was analyzed separately for male and female patients.

Cases studied were analyzed after being subdivided into a group with normal and a group with increased left ventricle mass. Means were determined separately according to sex, age group, body mass index, body surface, thoracic anterior-posterior diameter, thoracic perimeter, systolic and diastolic pressure, cardiac frequency, left ventricular mass proper, left ventricular mass/body surface, and each electrocardiographic criterion studied. Standard deviation of the mean was calculated using Fisher's statistical method. Age groups were determined according to Simone et al $^{19}$ for the population less than 18 years of age, and according to Levy et al ${ }^{16}$ for the population aged over 18 years. Sensitivity, specificity, positive and negative predictive values of each electrocardiographic criteria and were statistically analyzed with the statistical test for 2 independent groups. Results were considered statistically significant when having values $\leq 0.05$.

Finally, the study analyzed the relationship of the most sensitive electrocardiographic criteria with age, anteriorposterior thoracic diameter, thoracic perimeter, and left ventricular mass in the population of individuals considered normal, separated for male and female sex, to evaluate the influences of such variables on these methods.

\section{Results}

Three hundred six subjects, 85 with increased left ventricular mass (LVM) based on echocardiographic findings and 221 with normal LVM, were studied according to age, sex, body surface and body mass index.

The clinically normal population, ie, those having echocardiographically determined normal LVM, comprised 76 women and 63 men. Various population characteristics were determined from this normal subgroup. A progressive increase of LVM with aging was found (Figure 1). In contrast with earlier tracings, no significant variation due to age was noted, values remaining constant in the diverse age groups (Figure 2), when LVM was corrected for body surface. The study of normal subjects showed an increased LVM proportional to body mass index and body surface (not presented here). Tracings of normal individuals aided in the evaluation of other members of the cohort, by determining those with increased ventricular mass.

Compared with the normal members of the population analyzed, higher average age was observed in subjects with LVH, both male and female. Women with LVH averaged 44.02 years of age, while normal subjects were 27.46 years old $(\mathrm{P} \leq 0.001)$. Among men, normal individuals averaged

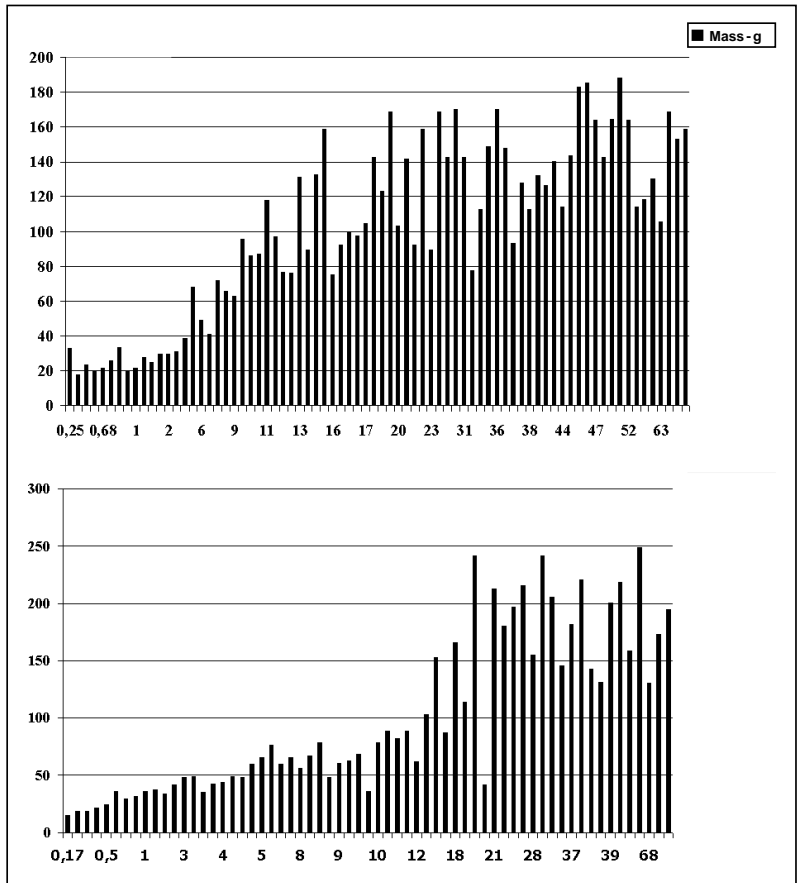

Fig. 1 - Left ventricular mass according to age in normal women (upper panel) and men (lower panel).

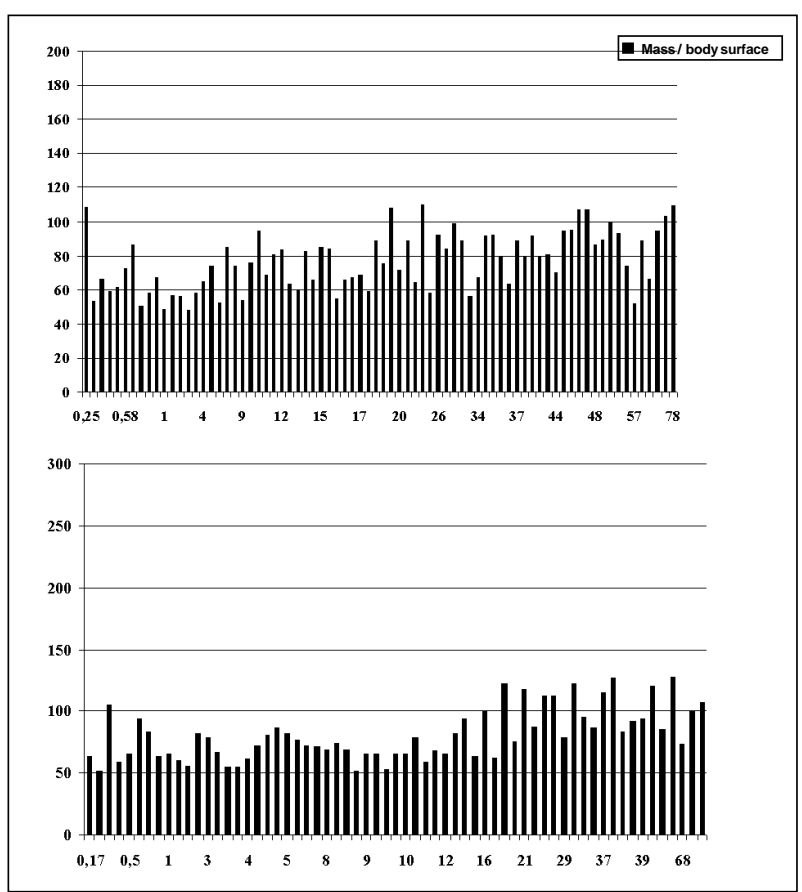

Fig. 2 - Left ventricular mass / body surface area according to age in normal women (upper panel) and men (lower panel).

24.17 years of age, while those with LVH averaged 45.44 years $(\mathrm{P} \leq 0.001)$. Body mass indexes and body surface were greater in the majority of age groups having LVH compared with the normal group, but this difference was not significant. Mean values of systolic or diastolic arterial pressure, cardiac frequency, anterior-posterior thoracic diameter and 
thoracic perimeter did not differ among normal individuals and those with LVH. The data show homogeneity in the anthropometric data, arterial blood pressure, and heart rate between individuals with or without LVH. As shown above, this similarity did not extend to mean age.

Tables I and II, respectively, show that in both sexes, all electrocardiographic studies had statistically significantly higher average values for the population with increased left ventricular mass in all age groups, maintaining a correlation between mean left ventricular mass measured prior to, and following, correction for body surface. Despite this, mean values of the electrocardiographic criteria for detection of left ventricular overload in individuals with increased left ventricular mass remained below those considered maximal. Left ventricular mass was still within the range of what was considered normal by methods used even though it was still significantly higher than that in the normal group. This result was neatly brought out by the White-Bock criteria and the point scoring of Romhilt-Estes both for males and females. The Sokolow-Lyon and Sokolow-Lyon-Rappaport criteria had higher averages in individuals with LVH among young adults, but these values decreased gradually with aging. The Cornell criterion maintained high averages in young individuals with hypertrophy. These values also decreased gradually in older subjects, both in normal and hypertrophied women. In males, decreased average amplitudes were observed with increasing age, both in individuals with or without ventricular hypertrophy, except for a progressive increase in average amplitude based on the Cornell criterion, noted in normal subjects.

Results obtained for the correlation between electrocardiograms and echocardiograms were separated according to sex and initially described for 176 women. The echocardiogram demonstrated increased left ventricular mass in 51 women and normal values in 125. Comparisons of the Sokolow-Lyon and Sokolow-Lyon-Rappaport, Cornell, White-Bock, and Romhilt-Estes criteria with echocardiographic data are shown in Table III.

The Cornell criterion in women had the highest sensitivity, 54.905. It also had high specificity, 81.60\%. When this method was compared with that of the SokolowLyon-Rappaport criterion, the second showed $41.60 \%$ sensitivity, no significant difference between the methods being found $(\mathrm{P}=0.08)$ The same result occurred regarding specificity $(\mathrm{P}=0.14)$. The sensitivity of the Cornell criteria compared with the Sokolow-Lyon-Rappaport was significantly different $(\mathrm{P} \leq 0.05) 37.25 \%$. The methods were not different in specificity. The 3 criteria had statistically significantly higher sensitivity than those of White-Bock and Romhilt-Estes. The latter had the lowest indexes of sensitivity, but the highest, statistically significant specificity, in comparison with the other three.

Results obtained in men are depicted in Table IV. The high sensitivity (73.53\%) of the Sokolow-Lyon-Rappaport criterion contrasts with its low sensitivity of $40.63 \%$. The Sokolow-Lyon criterion had a greater sensitivity of $73.53 \%$ compared with that of the former $(\mathrm{P} \leq 0.01)$. Sensitivity was low at $50 \%$.

The White-Bock and Romhilt-Estes criteria had low sensitivity but high specificity. No statistically significant difference occurred for the Cornell and Sokolow-Lyon criteria. Sensitivity differences of the Sokolow-LyonRappaport and Cornell were significant at $(\mathrm{P} \leq 0.01)$. Specificity of the Cornell criterion was greater than that of the Sokolow-Lyon and Sokolow-Lyon-Rappaport criteria ( $\mathrm{P} \leq 0.01$ for both comparisons).

In men, the Cornell criterion had low sensitivity, compared with that in women, where it had the greatest values. Analysis of this criterion, reducing the amplitude obtained by adding the voltages of the $\mathrm{R}$ wave in the aVL derivation to the $S$ wave on derivation $V_{3}$ from 28 to $24 \mathrm{~mm}$, as proposed by Verdecchia et $\mathrm{al}^{24}$ and corroborated by the data obtained from the averaged amplitudes of patients with LVH at various age levels (Table II), led to a reevaluation of the Cornell criterion, modified for men. The sensitivity of the Cornell criterion modified to $24 \mathrm{~mm}$ was $52.94 \%$, not statistically different $(\mathrm{P}=0.11)$ from that of the nonmodified method. Specificity of the modified criterion was $78.13 \%$, which is less than the specificity of the conventional method $(\mathrm{P} \leq 0.05)$. The modified method had a positive predictive value of $46.15 \%$ and a negative one of $82.42 \%$. The authors of the present study proposed verifying the data with an amplitude of $20 \mathrm{~mm}$. Sensitivity increased to $67.65 \%$, not significantly different from that with the Sokolow-Lyon and Sokolow-Lyon-Rappaport criteria. The conventional Cornell criterion with $24 \mathrm{~mm}$ amplitude occurred $(\mathrm{P}=0.11)$. However, a statistically significant difference relative to the conventional Cornell criterion occurred at $28 \mathrm{~mm}$. Specificity was reduced to $62.50 \%$, lower than that of all other methods, except that of the SokolowLyon-Rappaport criterion $(\mathrm{P} \leq 0.01)$, a method exhibiting greater sensitivity in men.

On comparing results obtained from men and women respectively, the present study demonstrated a greater sensitivity in the majority of electrocardiographic criteria in men with the exception of the Cornell criterion, which showed greater sensitivity in women.

Tracings obtained in normal men and women for the exponential correlation of age with voltages of the SokolowLyon-Rappaport, Sokolow-Lyon, and Cornell criteria are shown in Figure 3. A decrease in the amplitudes of the first 2 criteria with aging was observed both in men and women, while the Cornell amplitude increased slightly with aging in men and decreased slightly with aging in women.

Tracings showing the correlation between SokolowLyon-Rappaport, Sokolow-Lyon, and Cornell criteria with 


\begin{tabular}{|c|c|c|c|c|c|c|c|c|c|c|c|c|c|c|}
\hline $\begin{array}{l}\text { Idade } \\
\text { (anos) }\end{array}$ & & $0-5$ & & -13 & & -20 & & -29 & 30 & -39 & $40-$ & & $\geq 50$ & \\
\hline V.E. & Normal & Hipertrofiado & Normal & Hipertrofiado & o Normal & Hipertrofiado & Normal & Hipertrofiado & o Normal & Hipertrofiado & Normal $\mathrm{l}$ & Hipertrofiado & Norma $\mathrm{H}$ & lipertrofiado \\
\hline M & 41,61 & 75,18 & 81,32 & 92,73 & 118,65 & 262,34 & 131,92 & 242,18 & 131,23 & 220,28 & 142,15 & 236,02 & 138,68 & 267,85 \\
\hline d.p. & 37,75 & 61,58 & 26,83 & 33,81 & 26,85 & 0,00 & 27,14 & 25,37 & 31,77 & 50,65 & 23,82 & 51,22 & 28,63 & 81,12 \\
\hline $\mathrm{P}$ & \multicolumn{2}{|r|}{0,26} & \multicolumn{2}{|c|}{0,59} & \multicolumn{2}{|c|}{$\leq 0,0001$} & \multicolumn{2}{|c|}{$\leq 0,0001$} & \multicolumn{2}{|c|}{$\leq 0,0001$} & \multicolumn{2}{|c|}{$\leq 0,0001$} & \multicolumn{2}{|c|}{$\leq 0,0001$} \\
\hline $\mathrm{M} / \mathrm{SC}$ & 66,22 & 185,76 & 72,81 & 102,45 & 76,74 & 164,83 & 90,84 & 148,98 & 80,93 & 134,04 & 86,79 & 145,84 & 85,15 & 156,62 \\
\hline d.p. & 17,58 & 54,29 & 13,76 & 9,04 & 14,71 & 0,00 & 33,87 & 22,56 & 15,55 & 29,76 & 14,53 & 27,48 & 15,41 & 52,23 \\
\hline $\mathrm{P}$ & \multicolumn{2}{|c|}{$\leq 0,0001$} & \multicolumn{2}{|c|}{0,01} & \multicolumn{2}{|c|}{$\leq 0,0001$} & \multicolumn{2}{|c|}{$\leq 0,002$} & \multicolumn{2}{|c|}{$\leq 0,0001$} & \multicolumn{2}{|c|}{$\leq 0,0001$} & \multicolumn{2}{|c|}{$\leq 0,0001$} \\
\hline SL & 26,14 & 39,50 & 23,13 & 39,50 & 27,50 & 46,00 & 24,24 & 33,80 & 28,71 & 33,67 & 26,81 & 30,33 & 23,13 & 27,10 \\
\hline d.p & 6,33 & 4,95 & 5,57 & 6,36 & 9,21 & 0,00 & 7,62 & 5,93 & 17,10 & 10,63 & 11,90 & 8,06 & 8,72 & 11,80 \\
\hline $\mathrm{P}$ & \multicolumn{2}{|c|}{0,09} & \multicolumn{2}{|c|}{0,002} & \multicolumn{2}{|c|}{0,07} & \multicolumn{2}{|c|}{0,02} & \multicolumn{2}{|c|}{0,44} & \multicolumn{2}{|c|}{0,37} & \multicolumn{2}{|c|}{0,27} \\
\hline SLR & 33,91 & 48,00 & 30,00 & 46,00 & 31,81 & 62,00 & 27,77 & 40,60 & 24,77 & 37,89 & 28,24 & 33,75 & 23,44 & 28,52 \\
\hline d.p. & 7,98 & 2,83 & 7,68 & 8,49 & 9,04 & 0,00 & 8,58 & 4,22 & 8,11 & 13,26 & 10,56 & 9,71 & 12,63 & 10,40 \\
\hline $\mathrm{P}$ & \multicolumn{2}{|r|}{0,023} & \multicolumn{2}{|c|}{0,015} & \multicolumn{2}{|c|}{0,006} & \multicolumn{2}{|c|}{0,005} & \multicolumn{2}{|c|}{0,004} & \multicolumn{2}{|c|}{0,148} & \multicolumn{2}{|c|}{0,19} \\
\hline $\mathrm{C}$ & 17,82 & 32,00 & 12,27 & 30,00 & 12,88 & 21,00 & 13,18 & 19,00 & 12,94 & 19,56 & 12,67 & 22,25 & 15,25 & 20,33 \\
\hline d.p. & 4,33 & 12,73 & 4,38 & 2,83 & 8,07 & 0,00 & 7,49 & 8,22 & 5,97 & 11,72 & 4,91 & 10,23 & 9,23 & 9,80 \\
\hline $\mathrm{P}$ & \multicolumn{2}{|r|}{0,001} & \multicolumn{2}{|c|}{$\leq 0,0001$} & & 0,34 & & 0,15 & &, 07 & 0, & 001 & 0 , & \\
\hline WB & $-1,09$ & $-7,5$ & $-3,8$ & 17,50 & $-3,69$ & $-3,00$ & 1,35 & 7,20 & 4,06 & 4,00 & 3,81 & 7,67 & 5,50 & 9,57 \\
\hline d.p. & 10,29 & 7,78 & 7,84 & 0,71 & 10,84 & 0,00 & 10,06 & 14,76 & 8,93 & 13,89 & 7,77 & 13,62 & 9,87 & 10,19 \\
\hline $\mathrm{P}$ & & 0,40 & & ,002 & 0 & 95 & &, 32 & &, 99 & 0, & 31 & 0,2 & \\
\hline RE & 0,32 & 0,50 & 0,00 & 2,00 & 1,3 & 0,00 & 1,82 & 2,60 & 1,88 & 2,22 & 1,33 & 2,00 & 2,25 & 1,67 \\
\hline d.p. & 0,89 & 0,71 & 0,00 & 2,83 & 2,02 & 0,00 & 2,62 & 2,88 & 1,69 & 2,28 & 1,49 & 2,13 & 2,38 & 2,60 \\
\hline $\mathrm{P}$ & & 0,78 & &, 002 & & .54 & &, 58 & &, 67 & 0 , & 30 & 0 , & 49 \\
\hline
\end{tabular}

\begin{tabular}{|c|c|c|c|c|c|c|c|c|c|c|c|c|c|c|}
\hline \multirow{2}{*}{$\begin{array}{l}\begin{array}{l}\text { Tabel } \\
\text { (M/S }\end{array} \\
\begin{array}{l}\text { Idade } \\
\text { (anos) }\end{array} \\
\text { VE. }\end{array}$} & \multicolumn{2}{|c|}{$0-5$} & \multicolumn{2}{|c|}{$6-13$} & \multicolumn{2}{|c|}{$14-20$} & \multicolumn{2}{|c|}{$21-29$} & \multicolumn{2}{|c|}{$30-39$} & \multicolumn{2}{|c|}{$40-49$} & \multicolumn{2}{|c|}{$\geq 50$} \\
\hline & Normal & Hipertrofiado & Normal & Hipertrofiado & Normal & Hipertrofiado & Normal & Hipertrofiado & Normal & Hipertrofiado & Normal & Hipertrofiado & Normal l & lipertrofiado \\
\hline M & 40,68 & 51,24 & 77,30 & 149,36 & 119,35 & 316,60 & 193,07 & 291,72 & 182,45 & 282,92 & 179,30 & 330,07 & 185,36 & 310,95 \\
\hline d.p. & 15,70 & 4,36 & 23,91 & 56,45 & 53,98 & 44,10 & 27,17 & 71,40 & 29,95 & 21,78 & 36,95 & 97,61 & 43,57 & 84,22 \\
\hline$P$ & \multicolumn{2}{|c|}{0,36} & \multicolumn{2}{|c|}{0,002} & \multicolumn{2}{|c|}{0,001} & \multicolumn{2}{|c|}{0,004} & \multicolumn{2}{|c|}{$\leq 0,0001$} & \multicolumn{2}{|c|}{0,02} & \multicolumn{2}{|c|}{$\leq 0,0001$} \\
\hline $\mathrm{M} / \mathrm{SC}$ & 75,43 & 134,42 & 69,74 & 124,31 & 77,59 & 170,57 & 106,63 & 163,18 & 99,63 & 153,26 & 99,14 & 176,18 & 99,94 & 176,88 \\
\hline d.p. & 23,76 & 24,81 & 9,56 & 46,63 & 16,34 & 11,46 & 16,93 & 35,74 & 16,91 & 9,33 & 18,30 & 29,17 & 22,04 & 40,58 \\
\hline $\mathrm{P}$ & \multicolumn{2}{|c|}{0,003} & \multicolumn{2}{|c|}{$\leq 0,0001$} & \multicolumn{2}{|c|}{$\leq 0,0001$} & \multicolumn{2}{|c|}{0,004} & \multicolumn{2}{|c|}{$\leq 0,0001$} & \multicolumn{2}{|c|}{0,007} & \multicolumn{2}{|c|}{$\leq 0,0001$} \\
\hline SL & 30,08 & 29,20 & 31,59 & 35,50 & 26,67 & 55,33 & 33,10 & 61,00 & 30,96 & 37,33 & 28,20 & 41,50 & 32,33 & 34,80 \\
\hline d.p & 8,67 & 20,51 & 7,84 & 4,95 & 10,23 & 18,90 & 12,03 & 11,73 & 7,68 & 8,51 & 6,46 & 19,09 & 15,69 & 12,90 \\
\hline$P$ & \multicolumn{2}{|c|}{0,93} & \multicolumn{2}{|c|}{0,88} & \multicolumn{2}{|c|}{0,15} & \multicolumn{2}{|c|}{0,01} & \multicolumn{2}{|c|}{0,20} & \multicolumn{2}{|c|}{0,18} & \multicolumn{2}{|c|}{0,63} \\
\hline SLR & 33,92 & 38,50 & 41,06 & 41,00 & 33,00 & 58,33 & 36,60 & 32,00 & 35,09 & 48,33 & 40,60 & 49,00 & 34,08 & 39,30 \\
\hline d.p. & 7,80 & 16,26 & 6,96 & 1,41 & 10,43 & 19,14 & 12,03 & 25,46 & 8,22 & 8,74 & 7,54 & 7,07 & 20,14 & 15,12 \\
\hline$P$ & \multicolumn{2}{|c|}{0,46} & 0 , & 99 & 0 , & 03 & & 008 & 0 , & & & ,24 & 0 , & \\
\hline $\mathrm{C}$ & 16,75 & 34,00 & 17,24 & 25,50 & 16,83 & 26,00 & 19,50 & 33,50 & 18,77 & 21,33 & 18,20 & 21,50 & 21,17 & 23,85 \\
\hline d.p. & 5,47 & 1,41 & 5,70 & 6,36 & 3,97 & 18,25 & 6,15 & 16,26 & 8,36 & 5,13 & 5,40 & 9,19 & 11,47 & 10,26 \\
\hline $\mathrm{P}$ & & 0001 & 0 , & 07 & 0 & 25 & 0 , & 04 & 0, & & 0 , & 56 & 0 & \\
\hline WB & 0,88 & $-7,5$ & $-6,35$ & $-9,00$ & $-0,33$ & 6,33 & 2,80 & 13,00 & 4,46 & 10,67 & $-2,00$ & 14,00 & 11,33 & 10,75 \\
\hline d.p. & 9,32 & 19,09 & 6,52 & 22,63 & 12,64 & 23,12 & 12,59 & 5,66 & 12,10 & 1,53 & 5,83 & 7,07 & 10,27 & 12,18 \\
\hline P & & 26 & 0 , & 68 & 0,5 & & 0 & & 0,3 & & 0 , & 03 & 0 , & \\
\hline RE & 0,38 & 4,50 & 1,00 & 3,00 & 1,33 & 5,67 & 0,90 & 6,50 & 2,14 & 3,67 & 0,60 & 1,50 & 1,50 & 2,15 \\
\hline d.p. & 1,01 & 2,12 & 1,73 & 4,24 & 1,37 & 1,16 & 1,45 & 0,71 & 2,27 & 3,51 & 1,34 & 2,12 & 2,54 & 2,18 \\
\hline $\mathrm{P}$ & & 0001 & 0, & & 0,0 & & & 0001 & 0,3 & & 0 , & 51 & 0 , & \\
\hline
\end{tabular}

anterior-posterior diameters of the thorax are shown in Figure 4. A marked decrease in the amplitudes of the 3 voltages is observed in women with an increase in the diameter, a less marked decrease in the voltage of the Sokolow-LyonRappaport criterion occurring in men, and practically no alterations in the Sokolow-Lyon and Cornell criteria in men.
Analysis of the relation between thoracic perimeter and the voltages of the 3 criteria showed a direct graphic correlation with the anterior-posterior thoracic diameter and was therefore not represented here.

Finally, the study analyzed the relation between voltage of the Sokolow-Lyon-Rappaport, Sokolow-Lyon, 


\begin{tabular}{|lccccc|}
\hline $\begin{array}{l}\text { Tabela III - Comparação dos resultados comparativos com o } \\
\text { ecocardiograma dos critérios eletrocardiográficos nas mulheres. } \\
\text { Os resultados verdadeiro negativo, falso positivo, falso negativo e } \\
\text { verdadeiro positivo estão expressos em número de casos }\end{array}$ \\
\hline \multicolumn{5}{|c}{ Critério eletrocardiográfico: } \\
\cline { 2 - 6 } & $\begin{array}{l}\text { Sokolow } \\
\text { Lyon }\end{array}$ & $\begin{array}{c}\text { Sokolow-Lyon Cornell } \\
\text { Rappaport }\end{array}$ & $\begin{array}{c}\text { White } \\
\text { Bock }\end{array}$ & $\begin{array}{c}\text { Romhilt } \\
\text { e Estes }\end{array}$ \\
\hline $\begin{array}{l}\text { Verdadeiro } \\
\text { negativo }\end{array}$ & 111 & 95 & 102 & 116 & 117 \\
$\begin{array}{l}\text { Falso positivo } \\
\text { Falso negativo }\end{array}$ & 14 & 30 & 23 & 09 & 08 \\
$\begin{array}{l}\text { Verdadeiro } \\
\text { positivo }\end{array}$ & 19 & 30 & 23 & 40 & 46 \\
$\begin{array}{l}\text { Sensibilidade } \\
\text { Especificidade }\end{array}$ & $37,25 \%$ & $41,18 \%$ & $54,90 \%$ & $21,57 \%$ & $9,80 \%$ \\
$\begin{array}{l}\text { Valor preditivo } \\
\text { positivo }\end{array}$ & $57,80 \%$ & $76,00 \%$ & $81,60 \%$ & $92,80 \%$ & $93,60 \%$ \\
$\begin{array}{l}\text { Valor preditivo } \\
\text { negativo }\end{array}$ & $77,68 \%$ & $41,18 \%$ & $54,90 \%$ & $55,00 \%$ & $38,46 \%$ \\
\hline
\end{tabular}

\begin{tabular}{|c|c|c|c|c|c|}
\hline \multicolumn{6}{|c|}{$\begin{array}{l}\text { Tabela IV - Comparação dos resultados comparativos com o } \\
\text { ecocardiograma dos critérios eletrocardiográficos nos homens. Os } \\
\text { resultados verdadeiro negativo, falso positivo, falso negativo e } \\
\text { verdadeiro positivo estão expressos em número de casos }\end{array}$} \\
\hline & \multicolumn{5}{|c|}{ Critério eletrocardiográfico } \\
\hline & $\begin{array}{l}\text { Sokolow } \\
\text { Lyon }\end{array}$ & $\begin{array}{l}\text { Sokolow-Lyon } \\
\text { Rappaport }\end{array}$ & Cornell & $\begin{array}{l}\text { White } \\
\text { Bock }\end{array}$ & $\begin{array}{l}\text { Romhilt } \\
\text { e Estes }\end{array}$ \\
\hline Verdadeiro negativ & vo 69 & 39 & 87 & 86 & 90 \\
\hline Falso positivo & 27 & 57 & 09 & 10 & 06 \\
\hline Falso negativo & 17 & 09 & 21 & 23 & 22 \\
\hline Verdadeiro positiv & vo 17 & 25 & 13 & 11 & 12 \\
\hline Sensibilidade & $50,00 \%$ & $73,53 \%$ & $38,24 \%$ & $32,35 \%$ & $35,29 \%$ \\
\hline Especificidade & $71,88 \%$ & $40,63 \%$ & $90,63 \%$ & $89,58 \%$ & $93,75 \%$ \\
\hline $\begin{array}{l}\text { Valor preditivo } \\
\text { positivo }\end{array}$ & $38,63 \%$ & $30,49 \%$ & $59,09 \%$ & $52,38 \%$ & $66,66 \%$ \\
\hline $\begin{array}{l}\text { Valor preditivo } \\
\text { negativo }\end{array}$ & $80,23 \%$ & $81,25 \%$ & $80,55 \%$ & $78,90 \%$ & $80,36 \%$ \\
\hline
\end{tabular}

and Cornell criteria, with left ventricular mass obtained by echocardiography in individuals within the range of normality. Results showed that although an increase occurred in mass in contrast with what was expected, a progressive decrease in the voltages occurred in the Sokolow-Lyon-Rappaport, Sokolow-Lyon, and Cornell criteria, both in women and in men. Regarding the Cornell criterion, a progressive decrease in women and a discrete progressive increase in men were observed. The Cornell criterion was the only one to maintain a relationship with left ventricular mass, found only in men.

\section{Discussion}

Levy et al ${ }^{25}$ observed that despite the greater prevalence of LVH in women, the sensitivity of the electrocardiogram was lower. Our results demonstrate a lower sensitivity in 4 of the 5 electrocardiographic criteria studied in women. In males, left ventricular mass is proportionately greater than in females of the same age, weight, and body surface ${ }^{26}$. Levy et al ${ }^{27}$ pointed out that men have substantially larger hearts than do women, with greater mass even following adjustment for body surface.

Left ventricular mass determined by echocardiography was chosen as the gold standard for determining $\mathrm{LVH}$ to be used for the comparison with electrocardiographic data, because various previous reports showed a good correlation between this method and necropsy data ${ }^{28-31}$. According to the report, left ventricle dimensions were significantly correlated with the body surface area. Some studies use only height as a corrective factor, but it is known that this is not a good predictor of left ventricular mass, unlike weight or body surface ${ }^{32}$. Levy et al ${ }^{33}$ point out that the echocardiogram is a reference for studies on the evaluation of electrocardiographic criteria for detection of LVH. Left ventricular mass was calculated by the modified formula of the American Association of Echocardiography, showing greater facility by presenting values equal to those of the method established by the Pennsylvania Convention, a method more difficult to use and that offers the best correlation with necropsy data ${ }^{15,31,34-36}$. Using the formula of the American Association of Echocardiography for uncorrected data may overestimate left ventricular mass by up to $25 \%$, as demonstrated by Devereux et al ${ }^{31}$ and by up to $20 \%$ according to findings of Levy et al ${ }^{16}$. Average values for left ventricular mass of normal men and women found in the present study were similar to those reported in the literature ${ }^{15,16,18,19,22,26,27,36-44}$.

Average left ventricular mass corrected or not for body surface when compared with averages of the electrocardiographic criteria studied showed statistical relevance with the majority of the measurements by the Sokolow-LyonRappaport, Sokolow-Lyon, and Cornell criteria. This did not occur for the majority of the averages of the White-Bock and Romhilt-Estes criteria, among populations with or without hypertrophy. Curiously, these were the methods that showed least sensitivity, both in men and in women.

The Sokolow-Lyon criterion showed low sensitivity in women and a little greater sensitivity in men. The original study by these authors ${ }^{45}$ compared patients with already known cardiac disease with individuals known to be normal. That study showed a sensitivity of $32 \%$ and a specificity of $100 \%$. It analyzed the index in a population with LVH and greatly increased ventricular mass, of advanced age, comparing it with very young individuals with normal left ventricular mass, and analyzed men and women together. In comparison with the present study, it was found that sensitivity in women (37.25\%) was similar to the findings with Sokolow-Lyon criteria, while sensitivity in men was greater $(50 \%)$. Specificity in the present study was lower than that in the work cited, both in men and in women. The study of Casale et al ${ }^{10}$ comparing echocardiographic findings demonstrated that the Sokolow-Lyon index had a sensitivity of $33 \%$ and a specificity of $94 \%$, without separation by sex. Specificity was $100 \%$, which is greater than that found in the present study. Okin et al ${ }^{43}$ who evaluated 


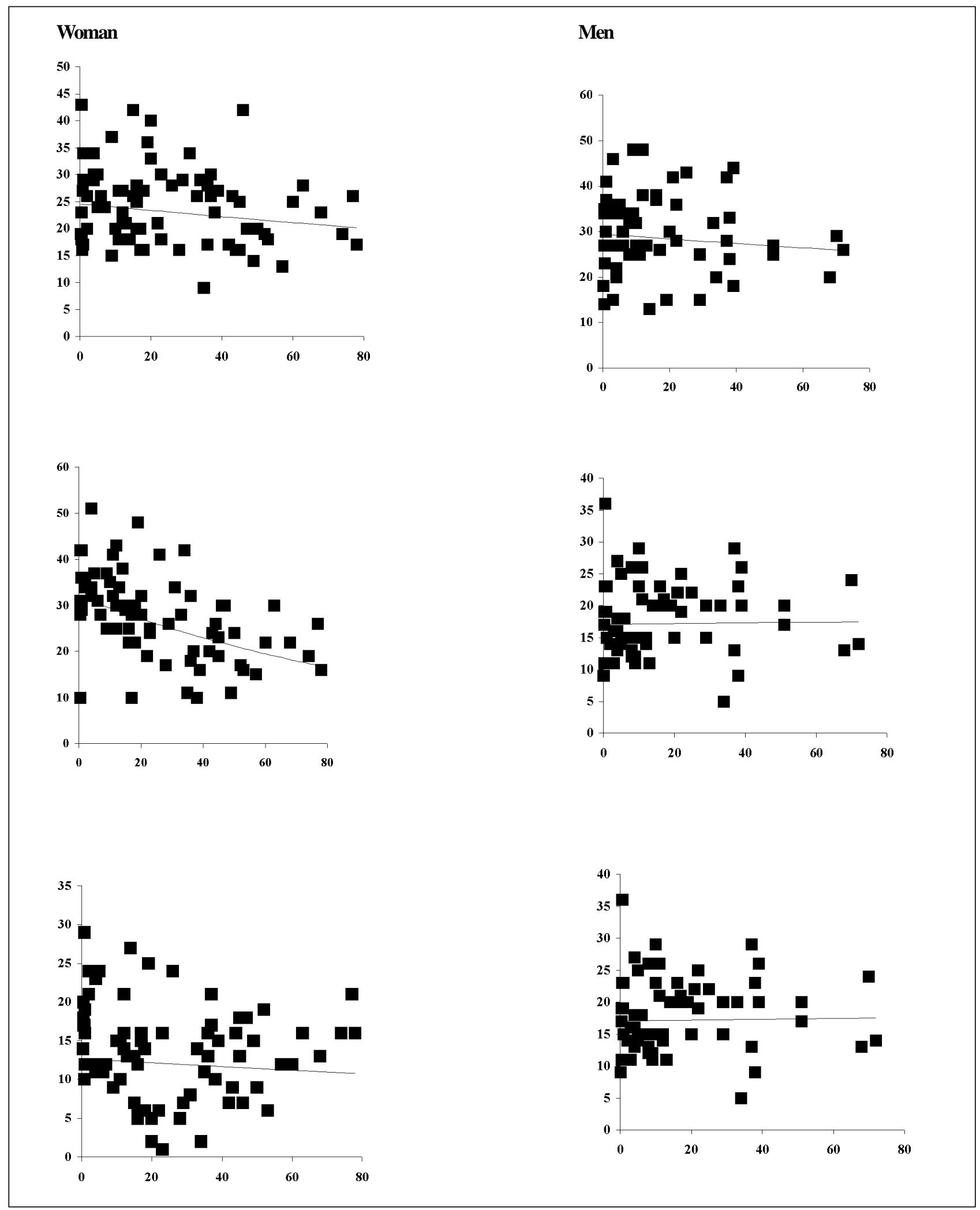

Fig. 3 -Exponential correlation in normal subjects of the following indexes: Sokolow - Lyon (top), Sokolow - Lyon -Rappaport (middle) and Cornell (bottom) with age.

echocardiograms in 62 normal men and 51 with LVH showed a $37 \%$ sensitivity and a $90 \%$ specificity for the SokolowLyon criterion, while our study showed greater sensitivity with lower specificity. Domingos et al ${ }^{46}$ demonstrated in their correlation between electrocardiographic criteria and echocardiographic findings performed in 30 persons, 18 being women, a $40 \%$ sensitivity with $100 \%$ specificity for the Sokolow-Lyon criterion, differing from our study, which 
had greater sensitivity in men and less sensitivity in women. The specificity in our material was lower that that found either in women or in men. Sensitivity was similar to that found in men. Devereux et al ${ }^{47}$ evaluated Sokolow-

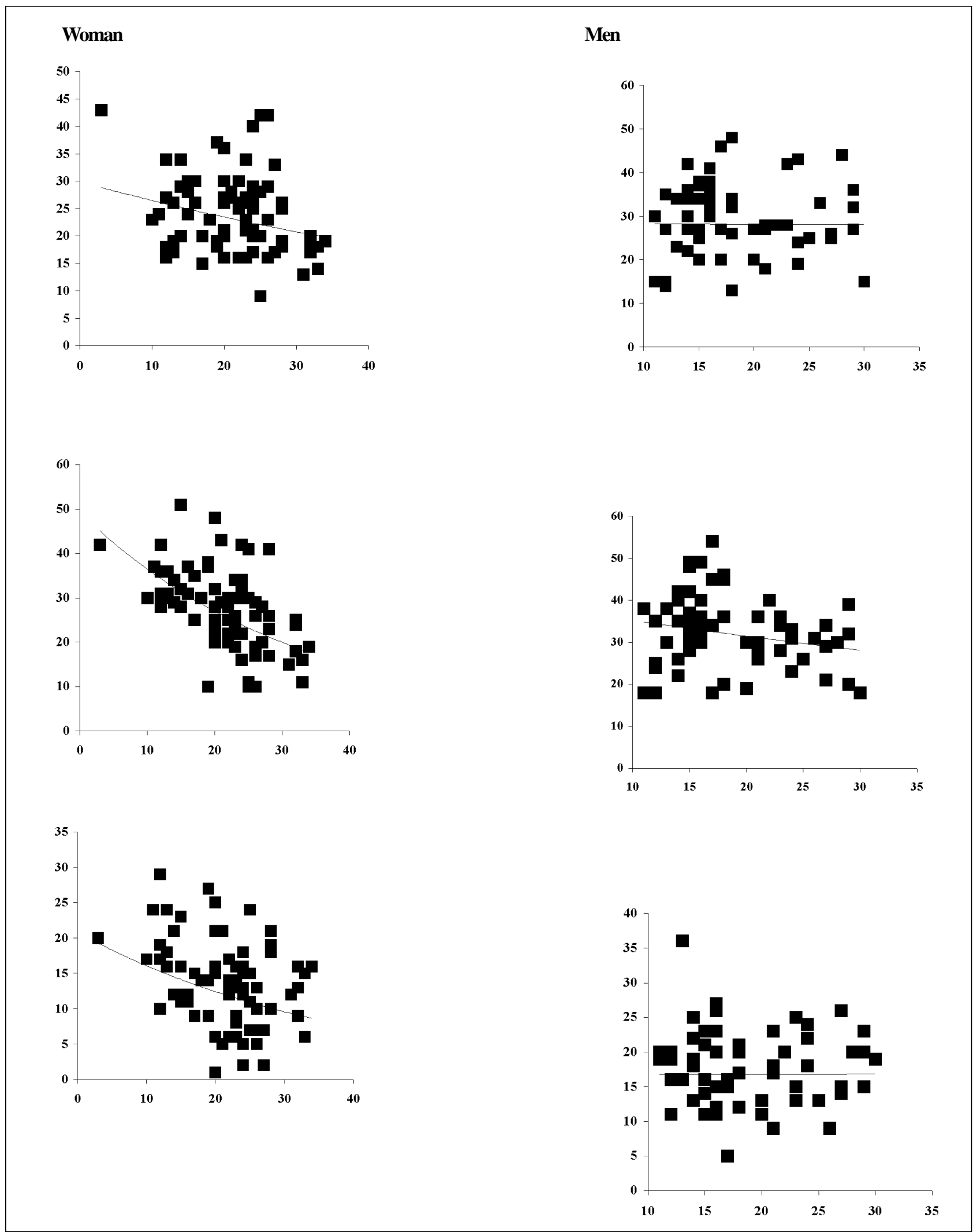

Fig. 4 - Exponential correlation in normal subjects of the following indexes: Sokolow -Lyon (top), Sokolow -Lyon-Rappaport (middle) and Cornell (bottom) with age with the antero posterior thoracic diameter. 
Lyon's criterion in comparison with echocardiographic findings and demonstrated a sensitivity of $22 \%$ and a specificity of $93 \%$. Our study demonstrated a lower sensitivity and specificity in both men and in women. The study by Bahler et $\mathrm{al}^{48}$ demonstrated a close correlation between the voltages of the Sokolow-Lyon index and the thickness of the intraventricular septum and not with the posterior wall of the left ventricle, which may explain different sensitivities found in these studies, the criteria being able to demonstrate greater sensitivity for some types of cardiac disease over others. The study by Fogel et al ${ }^{49}$ pointed this finding out. Feldman et al ${ }^{50}$ demonstrated a correlation between the R wave at the V5 and V6 derivations with an increase in the cardiac chamber, confirming this assertion.

The criterion of Sokolow-Lyon-Rappaport demonstrated greater sensitivity in men despite its low specificity. This index, which for many authors is a variation of the Sokolow-Lyon index, was analyzed separately because the presence of the sum of the $\mathrm{S}$ wave in the $\mathrm{V}_{2}$ derivation was not included in the original work ${ }^{51,52}$. Few reports exist in the literature of sensitivity and specificity values of this index. In the present study, the sensitivity of the Sokolow-LyonRappaport index was low in women. In men, the SokolowLyon-Rappaport criterion had a greater sensitivity than in women, perhaps due to the fact that mammae attenuate the detection of voltages by the electrocardiogram. As demonstrated, the increase in the anterior-posterior diameter and the thoracic perimeter led to a decreased amplitude in the voltages of this index, both in women and in men. The Sokolow-Lyon-Rappaport index had a statistically significant sensitivity relative to all other criteria in men. In contrast, specificity was low with values less than those of all other methods $(\mathrm{P} \leq 0.01)$.

The Cornell criterion had $41 \%$ sensitivity and $98 \%$ sensitivity in the study by Casale et al ${ }^{10}$, who developed this criterion when comparing electrocardiographic findings with those of echocardiography. These authors chose the aVL and $\mathrm{V}_{3}$ derivations to compose this index after analyzing the relation of the amplitudes of the voltages to LVH. They found that the $\mathrm{R}$ wave of the aVL derivation represented the axial deviation to the left of QRS. The $S$ wave of the $\mathrm{V}_{3}$ derivation represented the electromotive force of the left ventricle, directed towards the posterior region of the thorax, observed in the increases in the mass of the left ventricle. Women were analyzed together with men, with different values for men and women. The results of our study show that the Cornell sensitivity for women of $54.90 \%$ is greater than that of the original study. To determine normal maximal amplitudes, Casale et al ${ }^{10}$ used $20 \mathrm{~mm}$ for women and $28 \mathrm{~mm}$ for men, in random form, based on the analysis of the voltage differences between sexes, performed by the authors themselves. The low sensitivity for men relative to women found in our study stimulated the investigation of lower voltage amplitudes for the method, with the intention of improving its sensitivity. Levy et $\mathrm{al}^{25}$ had already declared that because the Cornell criterion considers left ventricular overload a lower amplitude for women, the index's sensitivity was greater in men compared with that in women, as observed in the present study. The same authors also cite that the index's sensitivity in men was $19 \%$, while in women it was of $22 \%$. Casale et al $^{53}$ analyzed the Cornell criterion developed by the authors in 135 patients, men and women, in comparison with pre-existing criteria and compared electrocardiographic criteria with findings at necropsy. The sensitivity of the Cornell criterion was $42 \%$, with a specificity of $96 \%$, which is similar to results obtained in the previous study by the same authors. Okin et $\mathrm{al}^{43}$ demonstrated a $22 \%$ sensitivity and an $87 \%$ specificity for the Cornell criterion in men. This low result of sensitivity was less than the result obtained in the present study. Specificity was also lower than that found in the present work. Domingos et $\mathrm{al}^{46}$ in the comparison between the Cornell criterion with echocardiographic findings found a $12 \%$ sensitivity and a $100 \%$ specificity. These results differ significantly from ours, probably due to the analysis performed by those authors involving a small cohort.

The method showing the highest sensitivity in women was Cornell's, while in men it was Sokolow-Lyon-Rappaport's. The Cornell criterion with an amplitude of $20 \mathrm{~mm}$ had a slightly lower sensitivity both in women and in men, which however was not statistically significant relative to the Sokolow-Lyon-Rappaport criterion, which had a greater specificity than the latter at $\mathrm{P} \leq 0.01$. Thus, the Cornell criterion at amplitude of $20 \mathrm{~mm}$, equal to that of women, was the sum of the voltages most adequate for this index in men.

The low sensitivity of the White-Bock criterion can be explained by the presence in many patients of an $\mathrm{S}$ wave in the DIII derivation, of little depth, often leaving the values of this criterion negative. The $\mathrm{S}$ wave of the derivation had greater voltages at the large axial deviations to the left of QRS, which is rarely seen in cases with light to moderate hypertrophy.

The point scoring of Romhilt-Estes had a $60 \%$ sensitivity and $98 \%$ specificity when the electrocardiogram was compared with findings at necropsy. The same study ${ }^{54}$ used in its majority as population samples cases of serious cardiac disease, with large values of ventricular mass that could have led to overestimation of the method's sensitivity. Our study revealed a sensitivity in both sexes much lower than that presented by these authors. Specificity was high (94\%), similar to the findings in both sexes in our study. In the study by Casale et al $^{53}$, sensitivity of the Romhilt-Estes criterion was $33 \%$, similar to that found in the present work in men, and greater than that in women. Specificity was high at $94 \%$, similar to findings in both sexes in our study. Okin et al ${ }^{43}$ evaluated the point scoring in men, finding in comparison with the echocardiogram, a sensitivity of only $12 \%$, with a specificity of $100 \%$ for the Romhilt-Estes criterion. Devereux et al ${ }^{47}$ found a sensitivity of $34 \%$ and a specificity of $98 \%$ in the comparison with left ventricular mass shown by the echocardiogram, without differences between results for either sex. Sensitivity in that study was very close to sensitivity found in men in the present study. However, in our study, sensitivity in women was much lower than that found by those authors. 
The point scoring of Romhilt-Estes showed a low correlation with the echocardiogram, and also was a difficult method to apply, because it was dependent on a close subjective analysis, which may generate doubts and cannot always be regularly applied, as for instance, in atrial fibrillation.

Molloy et $\mathrm{al}^{2}$ evaluated various electrocardiographic criteria obtained in comparison with necropsy findings. Sensitivity obtained with the Sokolow-Lyon criterion was $24 \%$ and $36 \%$ for the Cornell criterion. A systematic error occurred in this study in which the authors inverted voltages between men and women, considering a voltage of $20 \mathrm{~mm}$ for men and of $28 \mathrm{~mm}$ for women for the Cornell criterion. This was exactly the opposite of what had been proposed by Casale et al ${ }^{10}$, the authors who created the criterion. The same voltage inversion error between sexes for the Cornell criterion was made by Okin et al ${ }^{55}$ where the sensitivity of the Cornell criterion was $24 \%$. The authors also analyzed the sensitivity of the Cornell criterion without correcting for sex, using an amplitude of $20 \mathrm{~mm}$ for both sexes. An increase in sensitivity to $45 \%$ occurred, this value being lower to that found in our study in both sexes when an amplitude of $20 \mathrm{~mm}$ was used in both cases.

On analyzing the influence of age, anterior-posterior thoracic diameter, thoracic perimeter, and left ventricular mass proper on the electrocardiographic criteria of highest sensitivity, a decrease in voltage amplitudes with aging was observed, with the exception of the Cornell criterion in men, which showed a slight increase. It is known that aging leads to increased left ventricular mass, predominant in the female sex ${ }^{56}$. Running against the progressive increase in left ventricular mass with aging, a decrease in voltage amplitude of the electrocardiographic criteria analyzed occurred, suggesting a drop in sensitivity of LVH detection methods with aging. The presence of higher voltage amplitudes in children and adolescents, leading to a greater number of false-positives with the Sokolow-Lyon and Sokolow-LyonRappaport methods, demonstrates a probable greater uptake of cardiac electrical impulses by the electrodes in these age groups, possibly due to the smaller distance of the thoracic wall in children compared with that in to adults. The presence of higher voltage amplitudes in children and adolescents has been well demonstrated ${ }^{57,58}$. Aging leads to a reduction in QRS complex amplitude, which can decrease the electrocardiographic sensitivity ${ }^{33}$. The same study showed a progressive ÂQRS deviation to the left with aging in both sexes; this would impair an evaluation of the QRS with the Romhilt-Estes criterion in the aged. The same would occur in the analysis of the duration of the QRS complex, which would increase with growth concomitantly with age ${ }^{59-61}$. Levy et al ${ }^{33}$ pointed out that the greater limitation of electrocardiographic criteria for the determination of left ventricular overload is the use of the same voltages to detect the abnormality in youngsters and in the aged. Yang and Macfarlane ${ }^{61}$ observed differences in the duration of the QRS complex between sexes, it being greater in men. This result was also demonstrated by Kannel ${ }^{59}$ introducing a difficulty in the evaluation of the duration of the QRS complex in men by with the Romhilt-Estes criterion.
The correlation of the electrocardiographic voltage findings with left ventricular mass demonstrates that with an increasing mass, a reduction in the voltage amplitudes with the Sokolow-Lyon and Sokolow-Lyon-Rappaport criteria occurred in men, and with the Sokolow-Lyon, Sokolow-Lyon-Rappaport, and Cornell criteria in women. The sole criterion that showed a discrete increase in voltage with increases in ventricular mass was the Cornell criterion. The findings demonstrated that these 3 criteria, which have the aim of detecting increased left ventricular mass, paradoxically decrease the voltage amplitude while increasing, suggesting that other phenomena may influence the detection of electrocardiographic voltages or directly affect the amplitude of cardiac electrical phenomena. The presence of ischemic cardiac disease and myocardial dilatation with ventricular hypertrophy determines the presence of irregular areas normal fibers alternating with thinned, necrotic, or inflamed fibers. This may explain the shortened voltages in some cardiac areas with an ensuing decrease in the sensitivity of the method ${ }^{62,63}$. The anterior-posterior diameter of the thorax seems to have exerted an influence on voltage amplitudes by which their increase causes a reduction in the amplitudes of for all criteria in women, suggesting a probable effect of the mammae on the reduction of the electrode capacity to capture cardiac electrical potentials. This was also observed by the Sokolow-Lyon-Rappaport criterion in men. In this case, practically noinfluence of the anterior-posterior diameter of the thorax existed on the electrocardiographic amplitudes of the Sokolow-Lyon-Rappaport criteria.

The analysis of the correlation of the Sokolow-Lyon, Sokolow-Lyon-Rappaport, and Cornell criteria in individuals with increased left ventricular mass demonstrated that in their majority a greater adjustment in these criteria occurs in the detection of left ventricular overload in individuals with LVH with increased diastolic dimensions in the left ventricle, compared with those with only the hypertrophy. Fogel et $\mathrm{al}^{49}$ observed in children and adults a higher sensitivity in the electrocardiogram of the Sokolow-Lyon criterion in patients with aortic stenosis compared with those having intraventricular septal defect. Verdeccia et $\mathrm{al}^{24}$ pointed out that sensitivity increases the greater the LVH. The electrocardiogram has been used to indicate the degree of severity of left ventricular hypertrophy. Cicogna ${ }^{64}$ proposed that the ratio between left ventricular mass and the size of the chamber may be used to determine the type of stimulus promoting the process of hypertrophy. According to the author, the ratio is increased by pressure overload and normal in volume overload. Ganau et $\mathrm{al}^{39}$ demonstrated that hypertensive patients have 4 types of ventricle geometry: normal, concentric remodeling of the ventricle, concentric hypertrophy, and eccentric hypertrophy. The type may influence the electrocardiographic findings. Deeper subsequent studies aimed at this finding using a larger cohort should be performed to better elucidate the question, but this was not our aim.

Several studies are trying to improve the sensitivity of known methods by correcting for different variables, including the product of the voltage direction of the QRS complex $^{2}$. The application of equations taking into consideration 
anthropometric measurements has also been amply analyzed $^{65}$. The application of corrective factors, mainly using technological advances in electrocardiographic equipment may significantly raise the sensitivity of the methods in a routine fashion in the same way as left ventricular mass is corrected by body surface obtained echocardiographically.

We conclude that the Cornell criterion had the greatest sensitivity in women, and the Sokolow-Lyon-Rappaport method was more sensitive in men. These methods, together with Sokolow-Lyon's, which uses the sum of fixed voltages, offer the advantage of easy application, but the disadvantage of applying the same index for all age groups without due correction. The Cornell criterion uses different amplitudes relative to sex. In this study, this correction decreased the method's sensitivity in men with a recovery of sensitivity when applied at the $20 \mathrm{~mm}$ amplitude voltage, as done in women. Sensitivity increased and no statistically significant difference existed relative to the Sokolow-LyonRappaport criterion, an index showing greater sensitivity and specificity in men $(\mathrm{P} \leq 0.01)$.

\section{Acknowledgments}

To Prof. Zélia Milléo Pavão for the critical analysis of the data for this work.

\section{References}

1. Kannel WB, Gordon T, Offut D. Left ventricular hypertrophy by electrocardiogram. prevalence, incidence, and mortality in the Framingham Study. Ann Intern Med 1969; 71: 89-105

2. Molloy TJ, Okin PM, Devereux RB, et al. Electrocardiographic detection of lef ventricular hypertrophy by the simple qrs voltage - duration product. J Am Coll Cardiol 1992; 20: 1180-6.

3. Levy D, Garrison RJ, Savage DD, et al. Prognostic implications of echocardiographically determined left ventricular mass in the Framingham Heart Study. N Engl J Med 1990; 322: 1561-6.

4. Messerli FH, Aepfelbacher FC. Hypertension and Left-Ventricular hypertrophy. hypertension 1995; 13: 549-57.

5. Okin PM, Roman MJ, Devereux RB, et al. Time - voltage area of the QRS for the identification of left ventricular hypertrophy. Hypertension 1996; 27: 251-8.

6. Silva CES. Análise crítica do ecocardiograma na hipertrofia ventricular esquerda. Rev Soc Cardiol Estado de São Paulo 1994; 4: 361-8.

7. Norman JE, Levy D. Improved electrocardiographic detection of echocardiographic left ventricular hypertrophy: results of a correlated data base approach. J Am Coll Cardiol 1995; 26: 1022-9.

8. Arroyo JB, Braga JMS, Lina Filho B, et al. Análise crítica do eletrocardiograma e do vetorcardiograma no diagnóstico da hipertrofia ventricular esquerda. Rev Soc Cardiol Estado de São Paulo 1994; 4: 353-60

9. VerdecchiaP, Schillaci G, Borgioni C, et al. Prognostic significance of serial changes in left ventricular mass in essential hypertension. Circulation 1998; 97: 48-54.

10. Casale PN, Devereux RB, Kligfield P, et al. Electrocardiographic detection of left ventricular hypertrophy: development and prospective validation of improved criteria. J Am Coll Cardiol 1985; 6: 572-80.

11. Best CH, Taylor NB. (Eds.) As Bases Fisiológicas da Prática Médica. $2^{a}$.ed. Riode Janeiro: A Casa do Livro Ltda., 1946: vol. 2: 1-23.

12. Aurigemma GP, Gaasch WH, Villegas B, et al. Noninvasive assessment of left ventricular mass, chamber volume, and contractile function. Curr Probl Cardiol 1995; 20: 361-440.

13. Byrd III BF, Wahr D, Wang YS, et al. Left ventricular mass and volume/mass ratio determined by two-dimensional echocardiography in normal adults. J Am Coll Cardiol 1985; 6: 1021-5.

14. Casale PN, Devereux RB, Milner M, et al. Value of echocardiographic measurement of left ventricular mass in predicting cardiovascular morbid events in hypertensive men. Ann Intern Med 1986; 105: 173-8.

15. Moisés VA, Rivera IR, Plavinik F, et al. Comparação entre equações diferentes para o cálculo do índice de massa do ventrículo esquerdo pela ecocardiografia. Rev Bras Ecocardiogr 1996; 25: 22-6.

16. Levy D, Anderson KM, Savage DD, et al. Echocardiographically detected left ventricular hypertrophy: prevalence and risk factors. The Framingham Heart Study. Ann Intern Med 1988; 108: 7-13.

17. Feigenbaum H.Echocardiographic Evaluation of Cardiac Chambers. In:Feigenbaum H. (Ed.) Echocardiography. $5^{\text {h }}$ ed. Media: Lea \& Febiger, 1994: 134-58.

18. Abergel E, Tase M, Bohlender J, et al. Which definition for echocardiographic left ventricular hypertrophy? Am J Cardiol 1995; 75: 498-502.

19. Simone G, Daniels SR, Devereux RB, et al. Left ventricular mass and body size in normotensive children and adults: assessment of allometric relations and impact of overweight. J Am Coll Cardiol 1992; 20: 1251-60.

20. Daniels SR, Meyer RA, Liang Y, et al. Echocardiographically determined left ventricular mass index in normal children, adolescents and young adults. J Am Coll Cardiol 1988; 12: 703-8.

21. Brandão AA, Pozzan R, Albanesi Filho FM, et al. Role of Anthropometric indexes and blood pressure as determinants of left ventricular mass and geometry in adolescents. The Rio de Janeiro Study. Hypertension 1995; 26: 1190-4.

22. Hashida E, Nishi T. Constitucional and echocardiographic variability of the normal electrocardiogram in children. J Electrocardiol 1988; 21: 231-7.

23. Henry WL, Gardin JM, Ware JH. Echocardiographic measurements in normal subjects from infancy to old age. Circulation 1980; 62: 1054-61.

24. Verdecchia P, Schillaci G, Borgioni C, et al. Prognostic value of a new electrocardiographic method for diagnosis of left ventricular hypertrophy in essential hypertension. J Am Coll Cardiol 1998; 31: 383-90

25. Levy D, Labib SB, Anderson KM, et al. Determinants of sensitivity and specificity of electrocardiografic criteria for left ventricular hypertrophy. Circulation 1990; 81: 815-20.

26. Okin PM, Roman MJ, Devereux RB, et al. Gender differences and the electrocardiogram in left ventricular hypertrophy. Hypertension 1995; 25: 242-9.

27. Levy D, Savage DD, Garrison RJ, et al. Echocardiographic criteria for left venticular hypertrophy: The Framingham Heart Stydy. Am J Cardiol 1987; 59: 956-60.

28. Devereux RB. Detection of left ventricular hypertrophy by m-mode echocardiography. anatomic validation, standardization, and comparison to other methods. Hypertension 1987; 9: 19-26.

29. Devereux RB, Reichek N. Echocardiographic determination of left ventricular mass in man - anatomic validation of the method. Circulation 1977; 55: 613-8.

30. Reichek N, Helak J, Plappert T, et al. Anatomic validation of left ventricular mass estimates from clinical two-dimensional echocardiography: initial results. Circulation 1983; 67: 348-52.

31. Devereux RB, Alonso DR, Lutas EM, et al. Echocardiographic assessment of left ventricular hypertrophy: comparison to necropsy findings. Am J Cardiol 1986; 57: 450-8.

32. Gardin JM, Siscovick D, Anton-Culver H, et al. Sex, age, and disease affect echocardiographic left ventricular mass and systolic function in the free-living elderly. The Cardiovascular Health Study. Circulation 1995; 91: 1739-48.

33. Levy D, Bailey JJ, Garrison RJ, et al. Electrocardiographic changes with advancing age. J Electrocardiol 1987; 20(suppl): 44-7.

34. Reichek N. Standardization in the measurement of left ventricular wall mass. Mmode echocardiography. Hypertension 1987; 9: 27-9.

35. Schiller NB. Considerations in the standardization of measurement of left ventricular myocardial mass by two-dimensional echocardiography. Hypertension 1987; 9(suppl II): II-33-II-35

36. Park SH, Shub C, Nobrega TP, et al. Two-dimensional echocardiographic calculation of left ventricular mass as recommended by the american society of echocardiography: correlation with autopsy and M-mode echocardiography. J Am Soc Echocardiogr 1996; 9: 119-28. 
37. Devereux RB, Lutas EM, Casale PN, et al. Standardization of M-mode echocardiographic left ventricular anatomic measurements. J Am Coll Cardiol 1984; 4 : 1222-30.

38. Ferreira C, Póvoa R, Ferreira Filho C, et al. Hipertrofia e hipertensão. Rev Bras Hipert 1997; 4: 235-40.

39. Ganau A, Devereux RB, Roman MJ, et al. Patterns of left ventricular hypertrophy and geometric remodeling in essential hypertension. J Am Coll Cardiol 1992; 19: $1550-8$.

40. Koren MJ, Devereaux RB, Casale PN, et al. Relation of left ventricular mass and geometry to morbidity in uncomplicated essential hypertension. Ann Intern Med 1991; 114: 345-52.

41. Lindroos M, Kupari M, Heikkilä J, et al. Echocardiographic evidence of ventricular hypertrophy in a general aged population. Am J Cardiol 1994; 74: 385 90.

42. Mandawat MK, Wallbridge DR, Pringle SD, et al. Heart rate variability in left ventricular hypertrophy. Br Heart J 1995; 73: 139-44.

43. Okin PM, Roman MJ, Devereux RB, et al. Electrocardiografic diagnosis of left ventricular hypertrophy by the time - voltage integral of the QRS complex. J Am Coll Cardiol 1994; 23: 133-40.

44. Simone G, Devereux RB, Ganau A, et al. Estimation of left ventricular chamber and stroke volume by limited $\mathrm{m}$ - mode echocardiography and validation by two-dimensional and Doppler echocardiography. Am J Cardiol 1996; 78: 801-7.

45. Sokolow M, Lyon TP. The ventricular complex in left ventricular hypertrophy as obtained by unipolar precordial and limb leads. Am Heart J 1949; 37: 161-86.

46. Domingos H, Luzio JCE, Lelesg N, et al. Correlação eletro-ecocardiográfica no diagnóstico da hipertrofia ventricular esquerda. Arq Bras Cardiol 1998; 71: 31-5.

47. Devereux RB, Casale PN, Eisenberg RR, et al. Electrocardiographic detection of left ventricular hypertrophy using echocardiographic determination of left ventricular mass as the reference standard. comparison of standard criteria, computer diagnosis and physician interpretation. J Am Coll Cardiol 1984; 3: 82-7.

48. Bahler AS, Teichholz LE, Gorlin R, et al. Correlations of electrocardiography and echocardiography in determination of left ventricular wall thickness: Study of apparently normal subjects. Am J Cardiol 1977; 39: 189-95.

49. Fogel MA, Lieb DR, Seliem MA. Validity of electrocardiographic criteria for left ventricular hypertrophy in children with pressure - or volume - loaded ventricles: comparison with echocardiographic left ventricular muscle mass. Pediatr Cardiol 1995; 16: 261-9.
50. Feldman T, Childers RW, Borrow KM, et al. Change in ventricular cavity size: differential effects on QRS and t wave amplitude. Circulation 1985; 72: 495-501.

51. Castellanos A, Kessler KM, Myerburg RJ. The Resting electrocardiogram. In: Schlant RC, Alexander RW. (Eds.) The Heart. $8^{\text {th }}$. ed. New York: McGraw - Hill, 1994: 321-56.

52. Goldberger AL. Eletrocardiography. In: Isselbacher KJ, Braunwald E. (Eds) Harrison's Principles of Internal Medicine. $13^{\text {th }}$ ed. New York: Mc Graw - Hill, 1994: vol.1: 954-66.

53. Casale PN, Devereux RB, Alonso DR, et al. Improved sex-specific criteria of left ventricular hypertrophy for clinical and computer interpretation of electrocardiograms: validation with autopsy findings. Circulation 1987; 75: 565-72.

54. Romhilt DW, Estes Jr. EH. A point-score system for the ECG diagnosis of left hypertrophy. Am Heart J 1968; 75: 752-8.

55. Okin PM, Roman MJ, Devereux RB, et al. Electrocardiographic identification of left ventricular hypertrophy: test performance in relation to definition of hypertrophy and presence of obesity. J Am Coll Cardiol 1996; 27: 124-31.

56. Dannenberg AL, Levy D, Garrison RJ. Impact of age on echocardiographic left ventricular mass in a healthy population (The Framingham Study). Am J Cardiol 1989; 64: 1066-8.

57. Strong WB, Downs TD, Liebman J, et al. The normal adolescent electrocardiogram. Am Heart J 1972; 83: 115-28.

58. Macfarlane PW, Coleman EN, Pomphrey EO, et al. normal limits of the high-fidelity pediatric ECG. J Electrocardiol 1989; 22(suppl): 162-8.

59. Kannel WB. Prevalence and natural history of electrocardiographic left ventricular hypertrophy. Am J Med 1983; 26: 4-11.

60. Macfarlane PW, Mc Laughlin SC, Devine B, et al. Effects of age, sex, and race on ECG interval measurements. J Electrocardiol 1994; 27(suppl): 14-19.

61. Yang T, Macfarlane PW. New sex dependent normal limits of signal averaged electrocardiogram. Br Heart J 1994; 72 : 197-200.

62. Zamorano MMB. Características anatomopatológicas da hipertrofia ventricular. Rev Soc Cardiol Estado de São Paulo 1994; 4: 320-7.

63. Weber KT, Brilla CG. Pathological hypertrophy and cardiac interstitium. fibrosis and renin-angiotensin-aldosterone system. Circulation 1991; 83: 1849-65.

64. Cicogna AC. Patogenia da hipertrofia cardíaca. Rev Soc Cardiol do Estado de São Paulo 1994; 4: 328-32.

65. Rautaharju PM, Manolio TA, Siscovick D, et al. Utility of new eletrocardiographic models for left ventricular mass in older adults. Hypertension 1996; 28: 8-15 